\title{
The Evaluation of Flexural Strength of Composite Resin Materials with and without Fiber
}

\author{
Mustafa Gundogdu ${ }^{1}$, Duygu Kurklu ${ }^{2}$, Nuran Yanikoglu ${ }^{3^{*}}$ and Esra Kul ${ }^{1}$ \\ ${ }^{1}$ Research Assistant, Department of Prosthodontics, Faculty of Dentistry, Atatürk University, Erzurum, Turkey \\ ${ }^{2}$ Assistant Professor, Department of Prosthodontics, Konak Dental Hospital, Izmir, Turkey \\ ${ }^{3}$ Professor, Department of Prosthodontics, Faculty of Dentistry, Atatürk University, Erzurum, Turkey
}

"Corresponding author: Prof. Dr. Nuran Yanikoglu, Atatürk University, Faculty of Dentistry, Department of Prosthodontics, Erzurum, Turkey, Tel: +90 442 236 0945 ; Email: ndinckal@atauni.edu.tr

Rec Date: Sep 23, 2014; Acc Date: Oct 24, 2014; Pub Date: Oct 31, 2014

Copyright: (c) 2014 Yanikoglu N, et al. This is an open-access article distributed under the terms of the Creative Commons Attribution License, which permits unrestricted use, distribution, and reproduction in any medium, provided the original author and source are credited.

\begin{abstract}
The aim of the present study was to evaluate the effect of solutions, times of storage and reinforcement with fiber on the flexural strength of different composite materials. Nanofill and nanohybrid composite materials with and without fiber, a glass fiber and polyethylene fiber, were tested in the present study. 72 specimens $\left(25 \times 2 \times 2 \mathrm{~mm} \mathrm{~m}^{3}\right)$ were prepared as following six groups; Group ECME: everStick Fibre / Clearfil Majesty Esthetics, Group EFU: ever Stick Fibre / Filtek Ultimate, Group RCME: Ribbond Fibre / Clearfil Majesty Esthetics, Group RFU: Ribbond Fibre / Filtek Ultimate, Group CME: Clearfil Majesty Esthetics, Group FU: Filtek Ultimate. The specimens were stored in distilled water and mouthwash and tested after 24 hours and 7 days. Data were analyzed using analysis of variance and Schefee test. It was found that the EFU group in distilled water for 24 hours had the highest flexural strength and the CME group in mouthwash for 7 days had the lowest flexural strength. The storage times and the solutions were not statistically significant factors affecting on the flexural strength. The mean flexural strength values of the RCME and the RFU groups were similar to the FU group.
\end{abstract}

Keywords: Composite resin materials; Fiber; Flexural strength

\section{Introduction}

Composite resins have found a wider area of utilization in the restoration of both anterior and posterior teeth as a result of the development of their esthetic and mechanical properties However, material properties must be further developed so as not to represent low fracture strength in the patients with parafunctional habits such as bruxism and under high stress areas such as cases requiring wide preparations including cusps, inlays or onlay restorations [1-5].

Fillers have been added to the composite resins to improve their esthetic and mechanical properties [5,6]. The amount and size of the filler, and the distribution of its particles affect physical and mechanical properties of composite resins [1,3,7]. Microfill composites have similar esthetical properties as enamel surface due to their low filler amounts. However, their mechanical properties are poor. Hybrid composites have superior mechanical properties than microfill composite resins because of their high filler amounts, and have acceptable esthetical properties $[1,3,8]$. Comparing the mechanical properties of nanohybrid and microhybrid composites showed that the nanohybrid had significantly superior properties [5]. Another method for improving the mechanical properties of dental polymers is addition of fibers $[9,10]$.

Fiber reinforced composite resins (FRCs) have been extensively used since 1960 [11] and currently represent a choice for clinical applications such as reinforcement of complete dentures and removable partial dentures, fixed partial dentures, endodontic posts, periodontal splints and orthodontic treatment as a retention splint [12-15]. Mechanical properties of FRCs applications depend on some factors like fiber orientations, fiber amount, adhesion of fibers to polymer matrix, impregnation of fiber with the matrix polymer, fiber type, fiber's aspect ratio and volume loading $[10,15,16]$.

There are several types of reinforcement fibers used in dental materials, but the most used are glass fiber, polyethylene fiber, kevlar, and carbon fiber [17-19]. These fibers are available pre- or nonimpregnated system. Impregnation of fibers with dental monomer systems having high viscosity is difficult. Gap and cracks caused by insufficient impregnation of fibers and insufficient adhesion between fibers and matrix result in an increase in water storage by FRCs. Increased water absorption of FRCs applications in an aqueous environment such as oral cavity cause a reduction in not only mechanical properties but also bending properties of FRCs restoration $[15,20]$ and hence affect its long term stability [21].

Properties of materials, such as fracture resistance and elasticity, under stress are evaluated by the determination of properties of flexural strength, flexural modulus, and fracture toughness [2]. While the failure stress of a material is called flexural strength, the stiffness of a material is called flexural modulus as both measured in bending [22] Flexural strength is important for composite designers because composite resins, especially cavities under stress, are exposed to tension and compression forces [1,2]. Thus the aim of the present study was to investigate the effect of fiber reinforcement and time of storage in different solutions on the flexural strength of composite resin materials.

\section{Materials and Methods}

In the present study, nanofill composite resin, nanohybrid composite resin, glass fiber, and polyethylene fiber were used. 
Producers and chemical composition of the materials were listed in Table 1. Rectangular specimens were prepared in stainless steel mold with internal dimensions of $25( \pm 2 \mathrm{~mm}) \times 2( \pm 0.1 \mathrm{~mm}) \times 2( \pm 0.1$ $\mathrm{mm}$ ), according to ISO 4049 Standard [23]. In the present study, 6 groups were formed, each having 12 specimens.

\begin{tabular}{|c|c|c|c|}
\hline Material & Producer & Chemical Composition & Lot no. \\
\hline $\begin{array}{l}\text { Clearfil Majesty } \\
\text { Esthetic (Nanohybrid) }\end{array}$ & Kuraray, Osaka, Japan & $\begin{array}{l}\text { Matrix: Bis-GMA, hydrophobicaromatic dimethacrylates, and } \\
\text { hydrophobicaliphatic dimethacrylates, dl-Camphorquinone } \\
\text { Filler: } 66 \text { vol\% ( } 78 \mathrm{wt} \%) \text { Silanated barium glass (average particle } \\
\text { size } 0.7 \mu \mathrm{m}) \text { and pre-polymerized organic filler }\end{array}$ & 0033AA \\
\hline Filtek Ultimate (Nanofill) & 3M ESPE, St.Paul, MN, USA & $\begin{array}{l}\text { Matrix: Bis-GMA, UDMA, } \\
\text { TEGDMA, PEGDMA and Bis-EMA resins } \\
\text { Filler: Non-agglomerated/non-aggregated } 20 \mathrm{~nm} \text { silica filler, non- } \\
\text { agglomerated/non-aggregated } 4 \text { to } 11 \mathrm{~nm} \text { zirconia filler, and } \\
\text { aggregated zirconia/silica cluster filler (comprised of } 20 \mathrm{~nm} \text { silica } \\
\text { and } 4 \text { to } 11 \mathrm{~nm} \text { zirconia particles) }\end{array}$ & N185323 \\
\hline everStick C\&B & Stick Tech Ltd, Turku, Finland & E-glass fibers, PMMA, Bis-GMA & 2101216-ES-279 \\
\hline Ribbond & $\begin{array}{l}\text { Ribbond Inc, Seattle,Washington, } \\
\text { USA }\end{array}$ & UHMWPE, Bis-GMA & 416120 \\
\hline $\begin{array}{l}\text { Bis-GMA, bisphenol A-gl } \\
\text { UDMA, urethane dimethe } \\
\text { TEGDMA, triethyleneglyc } \\
\text { PEGDMA, polyethylene } \\
\text { Bis-EMA, ethoxylated bis } \\
\text { PMMA, poly methyl meth } \\
\text { UHMWPE, ultra high mol }\end{array}$ & $\begin{array}{l}\text { yl dimethacrylate. } \\
\text { late } \\
\text { imethacrylate } \\
\text { ol dimethacrylate } \\
\text { nol a dimethacrylate } \\
\text { ylate } \\
\text { lar weight polyethylene }\end{array}$ & & \\
\hline
\end{tabular}

Table 1: Materials used in the research

Test specimens for each group were prepared in the following way:

Group ECME: E-glass fiber was placed at the bottom of the mold (tension side), and polymerized, by the directions of producer company. The rest of the mold was filled with nanohybrid composite, and polymerized on one side of the mold at each $1 / 3$ of specimen's length, by the directions of producer company.

Group EFU: E-glass fiber and nanofill composite resin were used in this group. Test specimens were prepared similarly as the ones in ECME group.

Group RCME: Polyethylene fiber was wetted with Single Bond (3M/ ESPE, St. Paul, MN, USA). Then, polyethylene fiber was placed at the bottom of the mold (tension side), and a layer of nanohybrid composite was placed on top of it. At each $1 / 3$ of specimen's length, fiber and composite resin were polymerized for 20 second duration. The rest of the mold was filled with nanohybrid composite and polymerized similarly.

Group RFU: Polyethylene fiber and nanofill composite resin were used in this group. Test specimens were prepared as the ones in RCME group.

Group CME: Nanohybrid composite resin was placed in a mold by the incremental techniques. Polymerization of both increments was realized on one side of the mold at each one-thirds of the side by the directions of producer company.

Group FU: Nanofill composite resin specimens were prepared as the ones in CME group.
All of the specimens were polymerized by using Henry Schein 1500 light curing unit (Henry Schein Inc., Melville, USA).

The color of composite resins used in the present study was A2. Just after specimens were prepared, half of the specimens in each group were placed in distilled water, and the other halves were placed in mouthwash (Kloroben, Drogsan, Turkey), and then kept at $37^{\circ} \mathrm{C}$ for 7 days. Half of the specimens in the solution were tested for 3-point bending test at the end of the 1st day while the other half were tested at the end of 7th day in the same manner to be able to derive conclusions whether the bending strength was changing with waiting duration.

Before the 3-point bending test was applied, specimens' dimensions were measured by a digital compass of 0.01 sensitivity. Measurements were performed at 3 points for the width and height, and their average values were used in the calculation of bending strength. The 3-point bend test was performed immediately after removing the specimens from the distilled water and without drying the specimens and was performed according to the ISO 4049 specifications in such a way that the diameter for both supports and the loading piston was $2 \mathrm{~mm}$ and the span in between supports was $20 \mathrm{~mm}$ (Figure 1). This test was performed by using Instron Universal testing instrument (Model 2519-106, Instron Corp, Norwood, Mass, USA), and cross head speed was adjusted as $0.1 \mathrm{~mm} / \mathrm{min}$. Maximum load was recorded before the fracture. Flexural strength was computed from: $\mathrm{S}=3 \mathrm{FL} / 2 \mathrm{bd}^{2}$, where $\mathrm{S}$ is the flexural strength (in $\mathrm{MPa}$ ), $\mathrm{F}$ is the maximum load applied to the specimen (Newton), $\mathrm{L}$ is the span in between the supports $(20 \mathrm{~mm})$, and $\mathrm{b}$ and $\mathrm{h}$ are respectively the width and height of the specimen in $\mathrm{mm}$. 
Citation: Gundogdu M, Kurklu D, Yanikoglu N, Kul E (2014) The Evaluation of Flexural Strength of Composite Resin Materials with and without
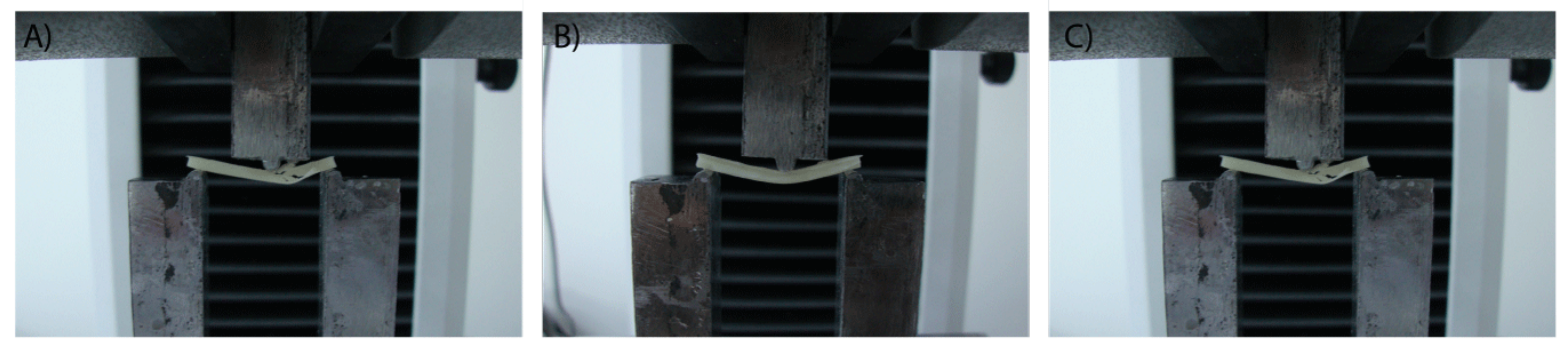

Figure 1: Fiber reinforced test specimen in 3-point bending test: (A) glass fiber reinforced composite resin; (B) glass fiber reinforced composite resin under flexure test; (C) cracked polyethylene fiber reinforced composite resin after flexure test.

A univariate analysis of variance (ANOVA) test was performed to determine the differences among the 6 groups and 2 solutions, followed by a post hoc Schefee test significant difference test with a confidence level of 0.05 to determine the mean differences. Differences between the storage times were analyzed with a paired sample $t$ test. The statistical analysis was performed with statistical software (SPSS v16.0; SPSS, Inc, Chicago, Ill).

\section{Results}

The minimum, maximum, mean and standard deviation values of $1^{\text {st }}$ and $7^{\text {th }}$ days are presented in Tables 2 and 3. The highest flexural strength values were observed in the EFU group in distilled water for 24 hours $(577.00 \pm 42.39 \mathrm{MPa})$ (Figure 2) and the lowest were observed in the CME group in mouthwash for 7 days (93.25 \pm 12.19 $\mathrm{MPa}$ ) (Figure 3).

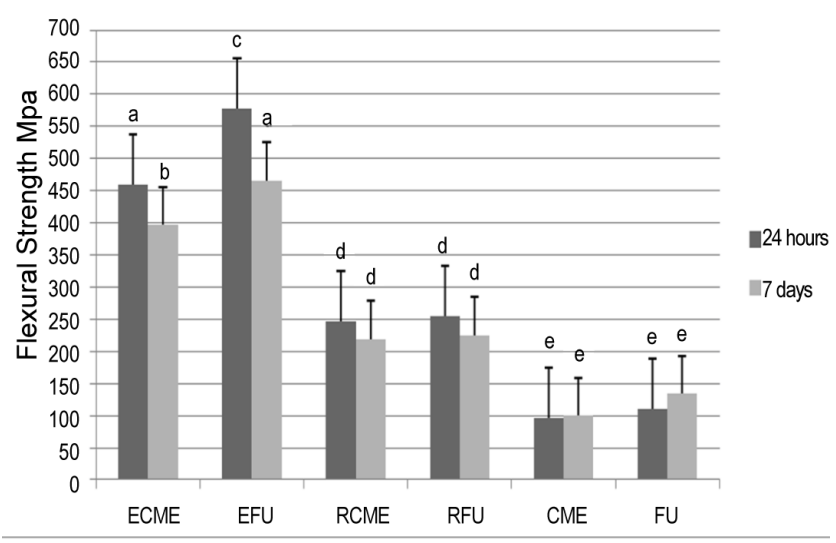

Figure 2: The mean flexural strength values of groups in stored distilled water for 24 hours and 7 days.

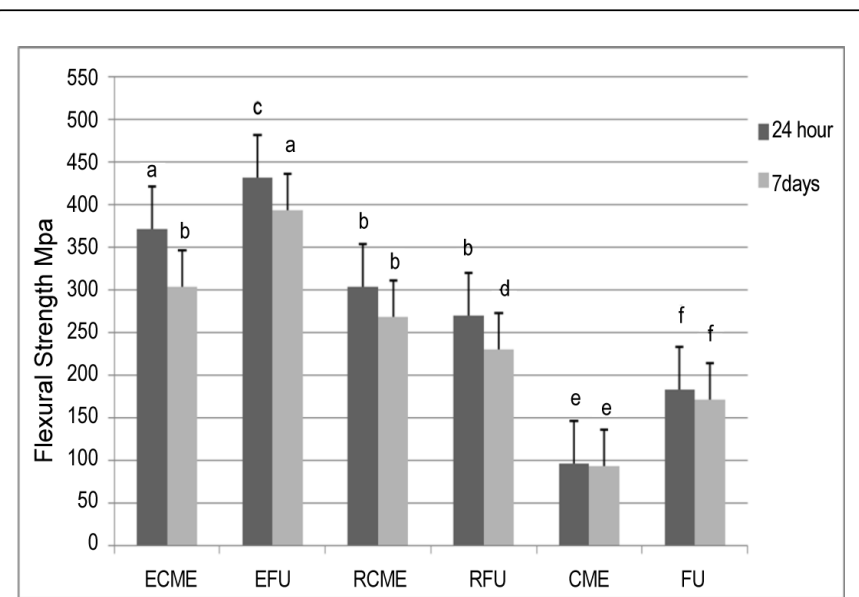

Figure 3: The mean flexural strength values of groups in stored mouthwash for 24 hours and 7 days.

\begin{tabular}{|l|l|l|l|l|}
\hline Groups & Minimum & Maximum & Means & Sd \\
\hline ECME & 227,25 & 539,25 & 415,06 & 118,80 \\
\hline EFU & 384,38 & 608,25 & 504,31 & 95,29 \\
\hline RCME & 210,38 & 310,50 & 275,13 & 46,77 \\
\hline
\end{tabular}




\begin{tabular}{|l|l|l|l|l|}
\hline RFU & 171,00 & 370,13 & 262,00 & 68,74 \\
\hline CME & 89,63 & 100,50 & 95,25 & 4,51 \\
\hline FU & 97,13 & 189,75 & 146,94 & 41,12 \\
\hline
\end{tabular}

Table 2: The minimum, maximum, means and standard deviation ( $\mathrm{Sd}$ ) values of specimens at first day (MPa)

\begin{tabular}{|l|l|l|l|l|}
\hline Groups & Minimum & Maximum & Means & Sd \\
\hline ECME & 237,38 & 530,63 & 350,06 & 109,26 \\
\hline EFU & 348,75 & 544,13 & 429,81 & 81,47 \\
\hline RCME & 113,25 & 293,25 & 243,19 & 66,50 \\
\hline RFU & 169,13 & 295,88 & 226,88 & 46,51 \\
\hline CME & 81,00 & 109,88 & 96,44 & 10,68 \\
\hline FU & 100,25 & 175,50 & 152,25 & 27,32 \\
\hline
\end{tabular}

Table 3: The minimum, maximum, means and standard deviation $(\mathrm{Sd})$ values of specimens at seventh day $(\mathrm{MPa})$

The mean flexural strength of the EFU and the ECME groups had significantly higher than that of the RFU and the RCME groups $(\mathrm{p}<0.05)$. However, no significant differences were found between the EFU and the ECME groups, and the RFU and the RCME groups ( $p>0.05)$. The RFU and the RCME groups had higher flexural strength values than the $\mathrm{FU}$ and the CME groups. A significant difference was noted between the CME group and the RFU, and the RCME groups $(\mathrm{p}<0.05)$; while no significant difference were found among the FU, the RFU, and the RCME groups $(\mathrm{p}>0.05)$. In addition, flexural strength of the CME and FU was not statistically different ( $p>0.05)$.

There was no statistically significant difference between the flexural strength of specimens in stored mouthwash and distilled water $(p>0.05)$ and between the immersion times $(p>0.05)$.

\section{Discussions}

Fisher et al. [24] observed a statistically significant difference in flexural strength among the composite resins in their research. They found that the flexural strength of nanofill composite resins were higher as compared to that of nanohybrid composite resins. Sideridou et al. [25] compared physical properties of 3 different nanohybrid and 2 nanofill composite resins in their study. After being kept in water for 1 day, specimens from nanofill composites (Filtek Supreme Body; FSB) had the highest flexural strength while the ones from nanohybrid composites (Tetric EvoCeram; TEC) had the lowest flexural strength. Statistically no significant difference was observed among the other composite resins (nanohybrid, Grandio, GR; nanohybrid, Protofillnao, nanofill, PR and Filtek Supreme Translucent, FST). After the specimens were kept in water for 30 days, the flexural strength of TEC stayed constant while the flexural strength of other composite resins decreased, and GR had highest flexural strength while TEC had the lowest flexural strength.
Rodrigues Junior et al. [26] investigated elasticity modulus and flexural strength of different kinds of composite resins. They found that microhybrid composite resins (Filtek Z-250, Esthet-X, respectively) had the highest flexural strength. Nanofill (Filtek Supreme) and microhybrid (Charisma) composite resins had similar flexural strength, and these presented higher flexural strengths than microfine (Helio Fill) composite resins.

In another study, researchers observed no statistically significant differences between the flexural strengths of microhybrid and nanofill composite resins [27]. In the present study, flexural strength of the FU group was higher than that of the CME group but the results were not statistically significant $(p>0.05)$. The variation among the results were thought of as originated from the difference in filler size, filler amount, polymer matrix, and coupling between filler and matrix in the composition of composite resins [2,22,28,29].

Fibers are used to improve the flexural strength of composite resins $[4,9,30]$. The orientation of fiber layer affects flexural strength of composite resins. When the fiber is placed at the bottom (tension side), the material has the highest flexural strength $[6,31]$. Therefore, in the present study, fiber layer was placed in the tension side. In composite resins reinforced with fibers, while cracks were observed in all composite resins after 3-point bending test, cracks were not observed in fiber materials but some bending existed. In an investigation performed previously, fracture was not observed in glass fiber materials [6]. Spyrides and Bastian [18] reported that while no delamination between the composite and fiber was observed in composites reinforced with glass fiber, delamination between the layers and cracks in the interface were observed in composite resins reinforced with polyethylene fibers. The same behavior was observed in the present study with the composite resins reinforced with polyethylene fiber (Figure 4). 

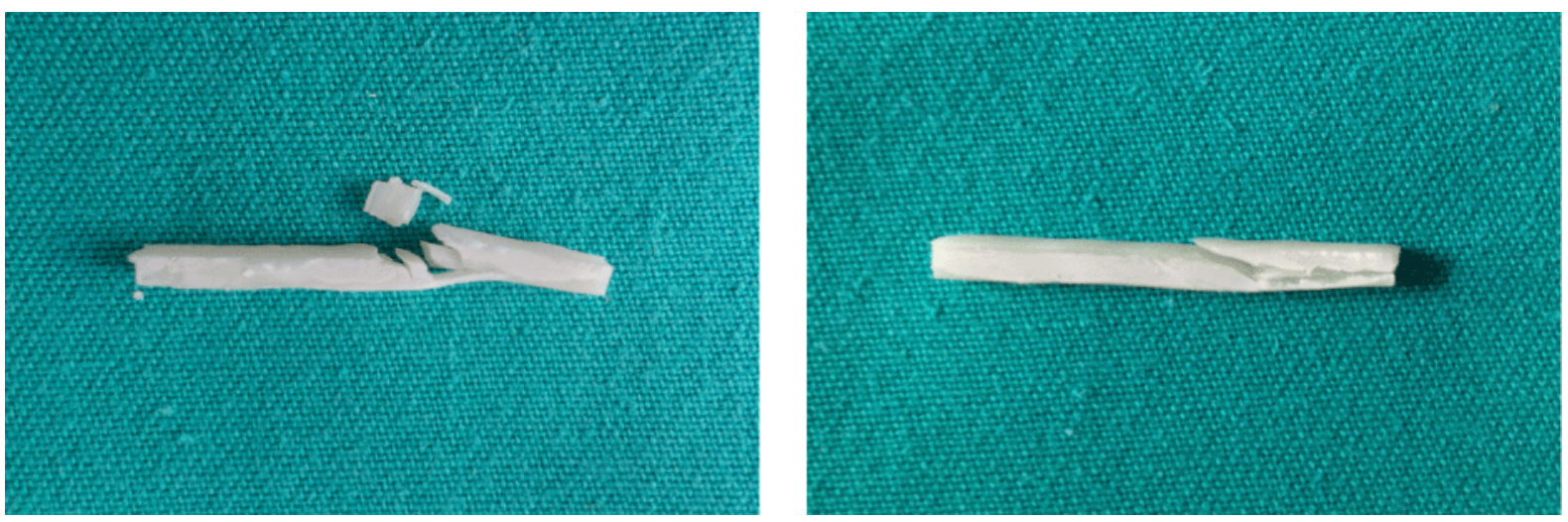

Figure 4: Cracked specimens after the 3-point bending test: (A) test specimen reinforced with glass fiber; (B) test specimen reinforced with polyethylene fiber.

Some studies were found similar results to the present study, and showed that the glass fibers had higher flexural strength than the polyethylene fibers [32-35]. Gaspar Junior et al. [36] compared the flexural strength and elasticity modulus of glass pre-impregnated fiber system and polyethylene non-impregnated fiber system. They stated that the flexural strength of non-impregnated polyethylene fiber was higher as compared to that of the pre-impregnated glass fiber, which is not the case in the present study. Spyrides and Bastian [18] stated that flexural strengths of polyethylene and glass fiber were statistically equivalent. In the present study, flexural strength of the EFU and the ECME groups was found to be higher as compared to the RCME and the RFU groups. Moreover, flexural strength of these four groups were higher than those of the FU and the CME.

The 3-point bending test is widely used for determining physical properties of composite resin materials $[1,2,28,30]$. Stress distribution in the 3-point bending test is similar to the stress distribution in fixed bridges. For this reason, the 3-point bending test was utilized to evaluate flexural properties of materials [30].

Fischer et al. [24] reported a significant increase in flexural strength of nanohybrid composite materials after being kept in water while there was a slight decrease in flexural strength of nanofill composite resins. Sideridou et al. [25] stated that no significant difference between the 1st and 30th days was observed in stored distilled water and artificial saliva. Rodrigues Filho et al. [37] stated that there was no significant decrease in the flexural strength of two different type of composite resins when they were kept in water. Gohring et al. [6] reported that flexural strength of glass fiber was affected by neither keeping in water nor thermocycling. Ellakwa et al. [17] observed a significant decrease in flexural strength of pre-impregnated-glass and UHMWPE fibers after storing in water for 6 months. Chai et al. [38] evaluated the effect of water sorption on flexural strength and flexural modulus of fiber reinforced composite resins. They reported that storing Stick and FibreKor specimens in distilled water for 1 day or 180 days had no significant difference on their flexural strengths. In the Vectris specimens they observed a significant decrease in flexural strength in the 180th day as compared to the 1st. There is little information about the effect of mouthwash on the flexural strength of fiber reinforced composite resins. Lahdenperä et al. [39] investigated flexural properties of glass fibre reinforced provisional fixed partial denture polymer and release of chlorhexidine digluconate, and stated no reduction in flexural strength of test specimens when the chlorhexidine digluconate-laced fibers were compared to those of conventional fiber reinforcements. In the present study, storing different solutions were no statistically significant on the flexural strength of fiber reinforced and unreinforced composite resins $(p>0.05)$. Moreover, flexural strength of the specimens slightly decreased in the 7 th day as compared to the 1st, but these results were not statistically significant $(\mathrm{p}>0.05)$.

The limitations of the present study include the absence of artificial aging, thermal cycling and the use of rectangular specimens instead of more complex fixed partial denture shapes. In vitro studies are limited in their ability to predict the success of a material or technique in a clinical situation. Within the limitations of the present study, it can be concluded that; flexural strength of composite resins improved with fibers and fiber type influenced the flexural strength. However, storage times and solutions had no significant effect on the flexural strength of test specimens.

\section{References}

1. Eronat N, Candan U, Türkün M (2009) Effects of glass fiber layering on the flexural strength of microfill and hybrid composites. J Esthet Restor Dent 21: 171-178.

2. Manhart J, Kunzelmann KH, Chen HY, Hickel R (2000) Mechanical properties and wear behavior of light-cured packable composite resins. Dent Mater 16: 33-40.

3. Ferracane JL (2011) Resin composite--state of the art. Dent Mater 27: 29-38.

4. Suzuki S, Saimi Y, Ono T (2006) Evaluation of a new fiber-reinforced resin composite.J Biomed Mater Res B Appl Biomater 76: 184-189.

5. Ilie N, Hickel R (2011) Resin composite restorative materials. Aust Dent J 56 Suppl 1: 59-66.

6. Göhring TN, Gallo L, Lüthy H (2005) Effect of water storage, thermocycling, the incorporation and site of placement of glass-fibers on the flexural strength of veneering composite. Dent Mater 21: 761-772.

7. Bayne SC, Heymann HO, Swift EJ Jr (1994) Update on dental composite restorations. J Am Dent Assoc 125: 687-701.

8. Pereira CL, Demarco FF, Cenci MS, Osinaga PW, Piovesan EM (2003) Flexural strength of composites: influences of polyethylene fiber reinforcement and type of composite. Clin Oral Investig 7: 116-119.

9. Xu HH, Schumacher GE, Eichmiller FC, Peterson RC, Antonucci JM, et al. (2003) Continuous-fiber preform reinforcement of dental resin composite restorations. Dent Mater 19: 523-530. 
10. Shouha P, Swain M, Ellakwa A (2014) The effect of fiber aspect ratio and volume loading on the flexural properties of flowable dental composite. See comment in PubMed Commons below Dent Mater 30: 1234-1244.

11. Goldberg AJ, Burstone CJ (1992) The use of continuous fiber reinforcement in dentistry. Dent Mater 8: 197-202.

12. Vallittu PK (1997) Glass fiber reinforcement in repaired acrylic resin removable dentures: preliminary results of a clinical study. Quintessence Int 28: 39-44.

13. Vallittu PK (1998) The effect of glass fiber reinforcement on the fracture resistance of a provisional fixed partial denture. J Prosthet Dent 79: 125-130.

14. Fredriksson M, Astbäck J, Pamenius M, Arvidson K (1998) A retrospective study of 236 patients with teeth restored by carbon fiberreinforced epoxy resin posts. J Prosthet Dent 80: 151-157.

15. Lassila LV, Nohrström T, Vallittu PK (2002) The influence of short-term water storage on the flexural properties of unidirectional glass fiberreinforced composites. Biomaterials 23: 2221-2229.

16. Behr M, Rosentritt M, Lang R, Handel G (2000) Flexural properties of fiber reinforced composite using a vacuum/pressure or a manual adaptation manufacturing process. J Dent 28: 509-514.

17. Ellakwa AE, Shortall AC, Marquis PM (2002) Influence of fiber type and wetting agent on the flexural properties of an indirect fiber reinforced composite. J Prosthet Dent 88: 485-490.

18. Spyrides SMM, Bastian FL (2004) In vitro comparative study of the mechanical behavior of a composite matrix reinforced by two types of fibers (polyethylene and glass). Materials Science \& Engineering CBiomimetic and Supramolecular Systems 24: 671-677.

19. Kumar G, Jain V, Pandey RK, Gadwal M (2014) Effect of Different Design Preparations on the Flexural and Fracture Strength of FiberReinforced Composite Fixed Partial Dentures: An In Vitro Study. J Prosthodont.

20. Miettinen VM, Narva KK, Vallittu PK (1999) Water sorption, solubility and effect of post-curing of glass fibre reinforced polymers. Biomaterials 20: 1187-1194.

21. Meriç G, Dahl JE, Ruyter IE (2005) Physicochemical evaluation of silicaglass fiber reinforced polymers for prosthodontic applications. Eur J Oral Sci 113: 258-264.

22. Yap AU, Teoh SH (2003) Comparison of flexural properties of composite restoratives using the ISO and mini-flexural tests. J Oral Rehabil 30 171-177.

23. International Organization for Standardization (2009) ISO 4049 Dentistry - Polymer-based restorative materials. Geneve: 1-28.

24. Fischer J, Roeske S, Stawarczyk B, Hämmerle CH (2010) Investigations in the correlation between Martens hardness and flexural strength of composite resin restorative materials. Dent Mater J 29: 188-192.

25. Sideridou ID, Karabela MM, Vouvoudi ECh (2011) Physical properties of current dental nanohybrid and nanofill light-cured resin composites. Dent Mater 27: 598-607.
26. Rodrigues Junior SA, Zanchi CH, Carvalho RV, Demarco FF (2007) Flexural strength and modulus of elasticity of different types of resinbased composites. Braz Oral Res 21: 16-21.

27. Rodrigues SA Jr, Ferracane JL, Della Bona A (2008) Flexural strength and Weibull analysis of a microhybrid and a nanofill composite evaluated by 3- and 4-point bending tests. Dent Mater 24: 426-431.

28. Chung SM, Yap AU, Chandra SP, Lim CT (2004) Flexural strength of dental composite restoratives: comparison of biaxial and three-point bending test. J Biomed Mater Res B Appl Biomater 71: 278-283.

29. Manhart J, Kunzelmann KH, Chen HY, Hickel R (2000) Mechanical properties of new composite restorative materials. J Biomed Mater Res 53: 353-361.

30. Ellakwa AE, Shortall AC, Shehata MK, Marquis PM (2001) The influence of fibre placement and position on the efficiency of reinforcement of fibre reinforced composite bridgework. J Oral Rehabil 28: 785-791.

31. Chung K, Lin T, Wang F (1998) Flexural strength of a provisional resin material with fibre addition. J Oral Rehabil 25: 214-217.

32. Alander P, Lassila LV, Tezvergil A, Vallittu PK (2004) Acoustic emission analysis of fiber-reinforced composite in flexural testing. See comment in PubMed Commons below Dent Mater 20: 305-312.

33. Schlichting LH, de Andrada MA, Vieira LC, de Oliveira Barra GM, Magne P (2010) Composite resin reinforced with pre-tensioned glass fibers. Influence of prestressing on flexural properties. Dent Mater 26: 118-125.

34. Sharafeddin F, Alavi A, Talei Z (2013) Flexural strength of glass and polyethylene fiber combined with three different composites. J Dent (Shiraz) 14: 13-19.

35. Juloski J, Beloica M, Goracci C, Chieffi N, Giovannetti A, et al. (2013) Shear bond strength to enamel and flexural strength of different fiberreinforced composites. J Adhes Dent 15: 123-130.

36. Gaspar Junior Ade A, Lopes MW, Gaspar Gda S, Braz R (2009) Comparative study of flexural strength and elasticity modulus in two types of direct fiber-reinforced systems. Braz Oral Res 23: 236-240.

37. Rodrigues Filho LE, Burger LA, Kenshima S, Bauer JR, Medeiros IS, et al. (2006) Effect of light-activation methods and water storage on the flexural strength of two composite resins and a compomer. Braz Oral Res 20: 143-147.

38. Chai J, Takahashi Y, Hisama K, Shimizu H (2005) Effect of water storage on the flexural properties of three glass fiber-reinforced composites. Int J Prosthodont 18: 28-33.

39. Lahdenperä MS, Puska MA, Alander PM, Waltimo T, Vallittu PK (2004) Release of chlorhexidine digluconate and flexural properties of glass fibre reinforced provisional fixed partial denture polymer. J Mater Sci Mater Med 15: 1349-1353. 